\title{
Completeness of information in electronic compared with paper-based patients' records in a maternity setting in Dakar, Senegal
}

\author{
Mame D. Ndiaye ${ }^{1,2} *$, Mamour Gueye ${ }^{1}$, Simon B. Ndour ${ }^{1,2}$, Ndama Niang ${ }^{1}$, Ndeye G. Fall ${ }^{1,2}$, \\ Khalifa Fall $^{1}$, Abdoulaye Diakhate ${ }^{1,2}$, Mouhamadou Wade ${ }^{1}$, Aliou Diouf ${ }^{1,2}$, \\ Moussa Diallo ${ }^{1}$, Magatte Mbaye ${ }^{1,2}$
}

\begin{abstract}
${ }^{1}$ Gynecologic and Obstetric Clinic, Aristide Le Dantec Teaching Hospital, PO Box 3001, Pasteur Avenue, Cheikh Anta Diop University, Dakar, Senegal

${ }^{2}$ Philippe Senghor Health Center, PO Box 29026 Dakar, Airport Road, Yoff, Cheikh Anta Diop University, Dakar, Senegal
\end{abstract}

Received: 18 January 2020

Revised: 20 February 2020

Accepted: 28 February 2020

*Correspondence:

Dr. Mame D. Ndiaye,

E-mail: diarryatoundiayegueye@gmail.com

Copyright: (C) the author(s), publisher and licensee Medip Academy. This is an open-access article distributed under the terms of the Creative Commons Attribution Non-Commercial License, which permits unrestricted non-commercial use, distribution, and reproduction in any medium, provided the original work is properly cited.

\begin{abstract}
Background: Evaluate the consistency of information in paper-based records when registered in parallel with an electronic medical record.

Methods: The study was performed at PMSHC in Dakar Senegal. From the end of year 2016, patients' files were recorded on both paper-based and electronically. Additionally, previous records were electronically registered. To investigate the completeness of records before and after the electronic recording system has been implemented, information about some maternal and fetal/neonatal characteristics were assessed. When the variable was recorded, the system returned 1 , unrecorded variables were coded as 0 . We then calculated, for each variable, the unrecorded rate before 2017 and after that date. The study period extended from 2011 to June 2019, a nearly ten-year period. Data were extracted from E-perinatal to MS excel 2019 then SPSS 25 software. Frequencies of unrecorded variables were compared with chi-squared test at a level of significance of $5 \%$.

Results: A total of 48,270 unique patients' records were identified during the eight-year period. Among the study population, data for patients' age, address and parity were available most of the time before and after $2017(0.5 \%$ missing data versus $0.3 \%$ for age and $2.6 \%$ versus $1.3 \%$ for home address and from $0.3 \%$ to $0.0 \%$ for parity). However, phone number, maternal weight, maternal height, last menstrual period and blood group were found to be missing up to $96 \%$ before 2017. From 2017, these rates experienced a sudden decrease at a significant level: from $82.4 \%$ to $27.8 \%$ for phone number, from $96 \%$ to $56.3 \%$ for maternal weight and from $60.1 \%$ to $21.3 \%$ for blood group. Regarding newborns' data, it was found that fetal height, head circumference and chest circumference were missing up to just under $25 \%$ before 2017. After that date, their completeness improved and flattened under $5 \%$.

Conclusions: Structured and computerized files reduce missing data. There is an urgent need the Ministry of health provides hospitals and health care providers with guidelines that describes the standardized information that should be gathered and shared in health and care records.
\end{abstract}

Keywords: Completeness, Dakar, Electronic medical record, Paper record, Senegal

\section{INTRODUCTION}

Consistency, reliability and exhaustivity of information in Medicine is the bedrock of any intervention aimed at improving health and health interventions particularly in the realm of maternal and child health. To preserve information collected on every day activity, processed, analysed and exchanged, databases are required, which 
necessarily implies computerization of the patient's record. ${ }^{1}$ Computing is not only a valuable aid for health care providers, it is at the heart of modern medicine, a medicine that requires information sharing between health system stakeholders and the patient in order to coordination and continuity of care.

Almost all hospitals in developed countries have electronic databases, including names, addresses, diagnoses, and treatments for all inpatients and outpatients. Investigators can acquire access to these databases to identify subjects for a study after gaining approval from a hospital's ethics committee. ${ }^{2}$

Just from a chronological perspective, several decades separate developed countries to Africa.

In a developing country where maternal mortality rate is still high, computerized information on pregnancy and birth is important for assessing the quality of maternal and new-born care. If reliable tools are available to continuously evaluate the prenatal period, childbirth and new-born care, these will allow health care managers to monitor the quality and impact of their actions to improve health care.

From the end of year 2016, the department has engaged in electronic medical records; patients' files were then recorded on both paper charts and electronically. On this background we wanted to evaluate the consistency of information in paper-based records when registered in parallel with an electronic medical record in a setting where paper semi-structured records are utilized. This hypothesis was that in semi-structured or unstructured paper records, doctors and midwives report information when they consider them relevant. Additionally, we wanted to put forward the necessity to implement widely the electronic medical recording system along with structured paper-based patient records.

\section{METHODS}

The study was performed at the Maternity of Philippe Maguilen Senghor Health Center (PMSHC) in Dakar Senegal. Senegal's health system consists of three main parts: a peripheral level, a regional and a central level. The peripheral level (that is, local community level) is known as "District sanitaire" with one health center and several primary care units. The regional intermediate level addresses problems of health of a given region/area. The central and national level holds the minister's office, subdivisions and related services.

Furthermore, facilities are made of three categories: national and regional hospitals, health centers and health posts. PMSHC is a level 2 health center. It does not have the performance of a hospital, but surgical procedures are performed. Teams of residents in obstetrics, midwives and nurses provide continuous emergency obstetric and newborn care (EmONC). On-call duties are carried under the supervision of an obstetrician. The setting has 34 beds. In 2018 , the number of deliveries encountered in the department was 8,172 and the number of outpatients encountered was 16,945 .

Senegalese Ministry of Health provide health facilities with semi-structured paper-based patient record templates. However, when it comes to informing important delivery-related events, no framework was available. Doctors register information they considered to be relevant.

From the end of year 2016, patients' files were recorded on both paper-based and electronically. Additionally, previous records were electronically registered.

\section{E-perinatal, an electronic medical record (EMR)}

The maternity of PMSHC has been actively working towards an improvement of completeness and exhaustivity of data engaging in electronic medical systems since the end of year 2016. Paper-based patient records were used in parallel.

E-perinatal is an electronic medical record system designed using File Maker Pro Inc. FileMaker was the only application with the necessary set of tools: a client/server application that works in a wireless local area network that could run on Windows or Mac OS laptops, mobile iOS devices and a doctor who had FileMaker developing skills. Databases can be shared simultaneously among multiple users, whether on Mac or Windows or kept as a single user. FileMaker databases can also be viewed on iPhone and iPad using the FileMaker Go app connection. The LAN allows access to the database system from each workstation in the center. The system itself provides quick access to all patient data (with access rights) and processing information and medical documentation. The system allows a quick query on all the patient's medical information. All data are readily available during the follow-up examination and are accessible at any time from any location of the center. The attending physician has more information on hand and can focus on the patient to provide a better service.

\section{Variables assessed}

To investigate the completeness of records before and after the electronic recording system had been implemented, information about some maternal and fetal/neonatal characteristics were assessed. When the variable was recorded, the system returned 1, unrecorded variables were coded as 0 . In this study, authors calculated for each variable, the unrecorded rate before 2017 and after that date. The study period extended from 2011 to June 2019, a nearly ten-year period. All patients' files were included in this study.

Frequencies of unrecorded variables were compared with chi-squared test at a level of significance of $5 \%$. 


\section{Statistical analysis}

Data were extracted from E-perinatal to MS excel 2019 then SPSS 25 software.

\section{RESULTS}

A total of 48,270 unique patients' records were identified during the eight-year period.

Table 1: Completeness of maternal and fetal/neonatal data before and after 2017.

\begin{tabular}{|c|c|c|c|}
\hline \multirow[t]{2}{*}{ Variables } & \multicolumn{2}{|c|}{ Missing data } & \multirow[t]{2}{*}{ p value } \\
\hline & $\begin{array}{l}\text { Before } \\
2017(\%)\end{array}$ & $\begin{array}{l}\text { After } \\
2017(\%)\end{array}$ & \\
\hline \multicolumn{4}{|c|}{ Information related to the mother and pregnancy } \\
\hline Phone number & 82.4 & 27.8 & $<0.001$ \\
\hline Address & 2.6 & 1.3 & $<0.001$ \\
\hline Patient age & 0.5 & 0.3 & $<0.001$ \\
\hline Marital status & 9.4 & 4.3 & $<0.001$ \\
\hline Maternal weight & 96.0 & 56.3 & $<0.001$ \\
\hline Maternal height & 92.4 & 73.0 & $<0.001$ \\
\hline $\begin{array}{l}\text { Number of antenatal } \\
\text { care visits }\end{array}$ & 23.2 & 5.3 & $<0.001$ \\
\hline $\begin{array}{l}\text { Last menstrual } \\
\text { period }\end{array}$ & 63.2 & 52.2 & $<0.001$ \\
\hline Public-fundal height & 19.0 & 6.9 & $<0.001$ \\
\hline Blood group & 60.1 & 21.3 & $<0.001$ \\
\hline Parity & 0.3 & 0.00 & $<0.001$ \\
\hline Tetanus vaccine & 11.5 & 4.8 & $<0.001$ \\
\hline $\begin{array}{l}\text { Intermittent } \\
\text { preventative } \\
\text { treatment of malaria }\end{array}$ & 13.8 & 8.9 & $<0.001$ \\
\hline \multicolumn{4}{|c|}{ Fetal and neonatal characteristics } \\
\hline Delivery time & 4.1 & 0.2 & \\
\hline Fetal weight & 0.5 & 0.5 & 0.431 \\
\hline Fetal height & 23.0 & 5.2 & $<0.001$ \\
\hline Head circumference & 21.4 & 4.9 & $<0.001$ \\
\hline Chest circumference & 22.9 & 5.6 & $<0.001$ \\
\hline Fetal presentation & 0.1 & 0.0 & $<0.001$ \\
\hline Baby's sex & 1.0 & 0.2 & $<0.001$ \\
\hline Fetal state & 0.1 & 0.1 & 0.564 \\
\hline Apgar score & 7.5 & 0.6 & $<0.001$ \\
\hline
\end{tabular}

Among the study population, data for patients' age, home address and parity were available most of the time before and after $2017(0.5 \%$ missing data versus $0.3 \%$ for age and $2.6 \%$ versus $1.3 \%$ for address and from $0.3 \%$ to $0.0 \%$ for parity). However, phone number, maternal weight, maternal height, last menstrual period and blood group were found to be missing up to $96 \%$ before 2017 . From 2017, these rates experienced a sudden decrease at a significant level: from $82.4 \%$ to $27.8 \%$ for phone number, from $96 \%$ to $56.3 \%$ for maternal weight and from $60.1 \%$ to $21.3 \%$ for blood group. Maternal height and last menstrual period levelled over $50 \%$ all the time as shown in Table 1.
Regarding new-borns' data, it was found that fetal height, head circumference and chest circumference were missing up to just under $25 \%$ before 2017. After that date, their completeness improved and flattened under $5 \%$. Other parameters such as baby's sex, fetal presentation and fetal weight were less of concern.

\section{DISCUSSION}

\section{Main findings}

The introduction of EMR system had a positive impact in the completeness of certain variables mainly those related to the field of obstetrics such as parity and newborn characteristics. However, even if some improvement was noted in regard with demographic characteristics, they were still missing up to $50 \%$ over both periods.

\section{A historical overview of the patient's record}

Edwin Smith Papyrus, the first known patient's record, is Egyptian from $1600 \mathrm{BC}$, a written document on papyrus describing surgical treatment of war wounds. ${ }^{3}$

Then followed the Greeks with Hippocrates, the father of medicine, who wrote careful notes of his patients about symptoms, appearance of the patient, social situation and other parameters to decide on the treatment. He recommended that these forms should be stored and used by new physicians involved in the treatment of the patient. ${ }^{4}$

The Arabs introduced the concept of hospital. They were the first to keep written records of patients and their medical treatment, which were later edited by doctors and referenced in future treatment. ${ }^{5}$

Later on, the first formal medical record system was developed in Sweden in 1752 and continuously refined until 1980 when computerized patient record systems started to become more common. ${ }^{4}$

\section{Paper-based patient's record}

There are several ways to write a medical record.

The source oriented patient record is divided based on the source from which the information is taken: the physician, the nurse, the laboratory or the radiology results and various other sources.

Medical records can also be designed as a problem oriented medical record (POMR). ${ }^{6}$ The model is based on an early decision on the main problem or problems of the patient, thereafter each problem is assessed on a daily basis without losing focus on the patient. The SOAP model originates from the POMR model stands for: subjective (anamnesis, actual reasons for visit), objective (findings when observing), assessment (analysis) and plan (treatment and healthcare plan). The paper record file gets thicker the more visits the patient has made. ${ }^{4}$ 
Both POMR and SOAP can be semi-structured or unstructured at all. The looser the structure of the document, the more the user is free in input, but the more difficult it becomes for the machine to process the content. The most irregular documents cannot directly fit a database data. Some systems allow to store these loose documents in the database of data either in the form of indivisible blocks or in a tree model representing the document nodes.

\section{Paper-based records compared to electronic medical records}

Unstructured handwritten patients' records use a free template and have several limitations. The handwriting is illegible, incomplete and the document cannot be electronically shared or stored. The information is not systematized, hence hardly computable and shareable. Paper records are also costly, need space to store, easy to destroy and difficult to analyze.

In our facilities, it is not seldom redrawing another patient record because of loss of the previous one, reordering a test because the results or the chart is missing. Needless to say, this leads to failure to provide important information and to provide efficient healthcare.

Unstructured data need then to be adapted for analysis. Throughout the abstraction methods literature, unstructured data is frequently discussed as challenging to reliably collect when compared to structured data. ${ }^{7-10}$ Semi-structured or structured patient files remain however paper files; therefore, risk of loss remains, and mandatory items are not always well filled.

Patient record text is different from standard text. Patient records contain plenty of misspellings (up to 10\%) and domain specific abbreviations (up to $10 \%$ ) and acronyms (up to $5 \%$ ). Patient records also contain incomplete sentences, often the subject or patient is missing in the sentence. ${ }^{4}$

Missing data found in this study were consistent with that of Mikkelsen who reported that seven percent of the electronic documents were significantly different in some way from the corresponding paper documents and $13 \%$ of the documents in the electronic record were missing. ${ }^{11}$ This fact can be the result of lack of congruity between the paper-based and the electronic records. This point is highlighted by Mikkelsen who suggests securing the validity of all versions of a record when implementing electronic record systems intended to operate in parallel with paper-based systems. ${ }^{11}$ Furthermore, when it comes to analyzing data, medical professionals should look toward combining information from both paper-based and electronic records as emphasized by Stausberg. ${ }^{12}$

In this study, demographic characteristics were missing most of the time even after implementing computerization. There is a need to raise awareness among health care providers about the importance of reporting data. Even if we do not yet face medico-legal complaints, it is important to not only be prepared to it but also notice that completeness of a medical records is crucial. Electronic medical record data represent a rich resource for clinical research.

Some factors were found to be associated with completeness of medical health records such as doctor's designation or type of complains. Lai et al, noted registrar and consultant documentations to be less complete than that of interns. History items were in addition better documented than examination items. ${ }^{13}$

It is much easier to retrieve and track patient's data using an electronic medical record paper chart reviews. Electronic medical records are much better organized than paper charts, allowing for faster retrieval of information.

Information collected on medical history, clinical and treatment need to be organized. Medical terminologies, classification systems and available controlled vocabularies are used in healthcare for that purpose. This system also includes ICD classification system. Its completeness was, however, not assessed in this study. Its full official name is International statistical classification of diseases and related health problems. ICD is increasingly used in clinical care and research to define diseases and study disease patterns, as well as manage health care, monitor outcomes and allocate resources. ICD is made of more than 1000 pages. Retrieving an information in hard paper might be tricky and very demanding. When anchored to EMR system, coding becomes easy and lead to completeness of diagnoses.

Even though FileMaker is really easy to use (especially compared to Microsoft SQL or Access), designing a complex database system still requires analytical skills and design expertise in both medicine and Informatics.

Electronic medical records reduce operating costs, increase quality and accuracy, decrease turnaround time, improve customer service, deliver a flexible and scalable solution and improve productivity. EMR are educational tools and allow for epidemiological studies, theses and dissertations. They help from regional or national authorities for annual national indicators, benchmarking to improve practices and aid for certification of health establishments.

The process for scaling from the paper unstructured file to the structured paper file and from the structured paper file to the electronic file is ongoing and allow shared files within a network of professionals.

\section{CONCLUSION}

The computerization of medical records requires a good structured tool and responsive IT specialists who listen to clinicians. It must be progressive, multidisciplinary and sharable. Otherwise, it does not provide all the services 
expected by clinicians. Structured and computerized files reduce missing data. There is an urgent need the Ministry of health provide hospitals and health care providers with guidelines that describes the standardized information that should be gathered and shared in health and care records.

\section{ACKNOWLEDGMENTS}

Authors would like to thank Ms. Adja Gueye Leye, Ms. Ndeye Maguette Sarre and Ms. Nafissatou Diene for their priceless help as well as the midwifes and obstetric residents of PMSHC and students who participated to populate this database.

Funding: No funding sources Conflict of interest: None declared

Ethical approval: The study was approved by the Institutional Ethics Committee

\section{REFERENCES}

1. Guèye $M$, Ndiaye Guèye $M D$, Mbaye $M$, Abdoulaye M, Diouf A, Wade M, et al. Crossing the line to electronic medical records in Subsaharian Africa: an obstetric and neonatal information system with perinatal indicators dashboard. J Health Sci Res. 2017;2(1):14-20.

2. Aschengrau A, Seage III GR. Essentials of epidemiology in public health. In: Burlington, MA: Jones and Bartlett Learning. $3^{\text {rd }}$ ed. Michael Brown Publisher; 2020:541.

3. Al-Awqati Q. How to write a case report: lessons from 1600 B.C. Kidney Inter. 2006;69(12):2113-4.

4. Dalianis H. Clinical text mining: Secondary Use of Electronic Patient Records. Springer, Cham; 2018:192.

5. Miller AC. Jundi-Shapur, bimaristans, and the rise of academic medical centres. J Royal Soci Med. 2006;99(12):615-7.

6. Weed LL. Medical records that guide and teach. New Eng J Med. 1968;278(12):652-7.
7. Engel L, Henderson C, Fergenbaum J, Colantonio A. Medical record review conduction model for improving interrater reliability of abstracting medical-related information. Eval Health Prof. 2009;32(3):281-98.

8. Hayward RA, Hofer TP. Estimating hospital deaths due to medical errors: preventability is in the eye of the reviewer. JAMA. 2001;286(4):415-20.

9. Reisch LM, Fosse JS, Beverly K, Yu O, Barlow WE, Harris EL, Rolnick S, Barton MB, Geiger AM, Herrinton LJ, Greene SM. Training, quality assurance, and assessment of medical record abstraction in a multisite study. Am J Epidemiol. 2003;157(6):546-51.

10. Stein HD, Nadkarni P, Erdos J, Miller PL. Exploring the degree of concordance of coded and textual data in answering clinical queries from a clinical data repository. J Am Med Inform Assoc. 2000;7(1):4254.

11. Mikkelsen G, Aasly J. Concordance of information in parallel electronic and paper-based patient records. Int J Med Inform. 2001;63(3):123-31.

12. Stausberg J, Koch D, Ingenerf J, Betzler $M$. Comparing paper-based with electronic patient records: lessons learned during a study on diagnosis and procedure codes. J Am Med Inform Assoc. 2003;10(5):470-7.

13. Lai FW, Kant JA, Dombagolla MH, Hendarto A, Ugoni A, Taylor DM. Variables associated with completeness of medical record documentation in the emergency department. Emerg Med Australas. 2019;31(4):632-8.

Cite this article as: Ndiaye MD, Gueye M, Ndour SB, Niang N, Fall NG, Fall K, et al. Completeness of information in electronic compared with paper-based patients' records in a maternity setting in Dakar, Senegal. Int J Reprod Contracept Obstet Gynecol 2020;9:1429-33. 